19 McGuire C. Assessing information needs. Health Visit 1992;65:268.

0 Department of Health National measles and rubella immunisation campaign. PL CMO(94)10. London: DOH, 1994.

21 Department of Health. Change to the routine pre-school booster immunisation programme. PL CMO (96)6. London: DOH, 1996.

2 Communicable Disease Surveillance Centre. MMR vaccine coverage falls in the United Kingdom. Commun Dis Rep CDR Wkly 1999;9:37.

23 Department of Health. Start of the new meningococcal $C$ conjugate vaccine immunisation programme. PL/CMO/99/4. London: $\mathrm{DOH}, 1999$.

24 British Market Research Bureau. The uptake of pre-school immunisation in England. Report on a national study of variation in immunisation uptake between District Health Authorities. London: Department of Health, 1989.

25 Begg NT, White JM. A survey of pre-school vaccination programmes in England and Wales. Community Med 1988;10:344-50.

26 Crittendem P, Rao M. The immunisation coordinator: improving uptake of childhood immunisation. Commun Dis Rev 1994;4:R79-81.

27 Campbell H. Health visitors' and practice nurses' attitudes to immunisation: a feasibility study. MSc Public Health. University of London, 1998.

28 Streetly A, Corbett V. The National Newborn Screening Programme. An audit of phenylketonuria and congenital hypothyroidism screening in England and of phenylketonuria and congenital hypothyroidism screening in

\section{Commentary}

After clean water and effective sewage disposal, immunisation is probably the greatest medical success story of all time, and the concept of the District Immunisation Coordinator is an excellent example of what can be achieved by a combination of a population wide perspective with clinical excellence.

The paper by Elliman and Morton omits a few points that will need consideration by Directors of Public Health and chief executives of Trusts. Perhaps the most important is the need to define how much time this job takes. There is a tendency seriously to underestimate the time needed to tackle public health tasks properly. The commitment can be virtually fulltime when there is major press coverage of a real or imagined scare, or a new programme such as meningococcal vaccine is launched; in between times, when all is working smoothly, the duties could easily be managed in one session a week or even less.

The second omission from the paper is the issue of the extent to which the District Immunisation Coordinator is responsible for various other infectious disease programmes - uptake and quality of hepatitis B prevention, flu immunisation campaigns which are mainly targeted at adults, advice on foreign travel, oversight of TB control including contact tracing as well as BCG, and immunisation of College students as a target group. It is most unlikely that there would ever be uniformity of the job plan for the District Immunisation Coordinator between districts, but it is important that all these tasks be allocated.

The model of the District Immunisation Coordinator can also be applied to other tasks-for example, neonatal hearing screening, PKU screening, childcare and so on. The principle of asking one individual to take on a defined task, set goals and report progress should be used more widely in community child health.

Lastly, there are obvious implications for the drafting of job descriptions, including a clear statement of accountability both for job plans and for the training needs of registrars and consultants who are asked to take on this role.

DAVID HALL

Professor of Community Paediatrics, Institute of General Practice, Community Service Centre, Herrics Road, Sheffield, South Yorkshire, UK

\title{
STAMPS IN PAEDIATRICS
}

\section{Immunisation}

Immunisation has been one of the major themes promoted on health stamps relating to paediatrics. Individual diseases - such as smallpox and polio, have been the focus occasionally although usually the general principles of immunisation

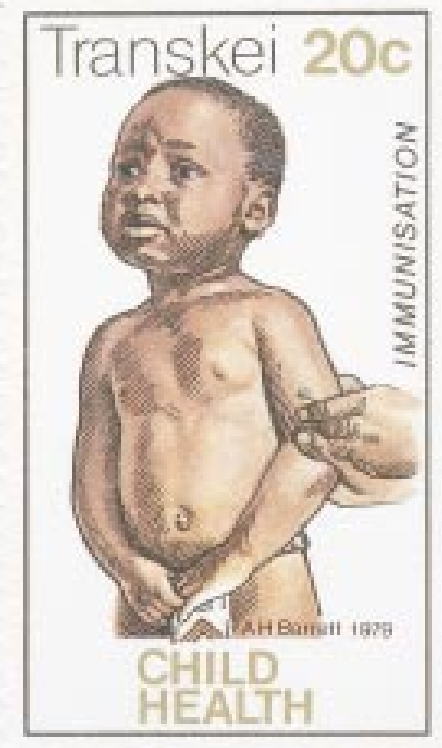

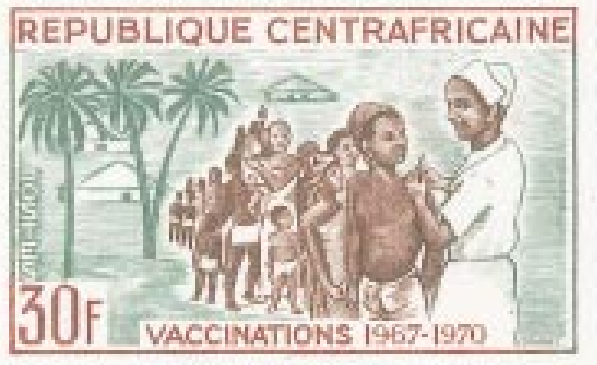

have been featured. These general principles are illustrated on these three stamps. The 1979 Transkei stamp was issued to promote child health and emphasises immunisation. The mass vaccination programme is highlighted and publicised on the Central African Republic stamp from 1967. The Grenada 1979 stamp commemorating the International Year of the Child celebrates the first nation to be $100 \%$ immunised and shows a vaccination gun and map of Grenada, together with the logo of the Rotary organisation. The individual diseases depicted are measles, diphtheria, whooping cough, polio, tetanus, tuberculosis, and typhoid.

M K DAVIES

A J MAYNE 